\title{
Through the shaving mirror
}

\section{... or, A tight night at the Surrealist Sporting Club.}

\section{Michael Moorcock, after Maurice \\ Richardson}

64 as anyone noticed," Monsignor Cornelius spoke urgently, hoping to divert Sir Perkin Float, on his third bottle of claret, from developing that familiar litany about discovering Chaos Math years before Mandelbrot, thus being cheated of his place in history and his video royalties, "how cats can turn off time? With a suitable lens, of course."

Engelbrecht, the dwarf metaphysical boxer, grew alert. Professional curiosity. A founder of the Surrealist Sporting Club, he refused to fight anything lighter than a cathedral clock. Against advice he'd challenged Big Ben to a 'no quarter' fin-de-millennium celebratory bout. Serious Soho backers. Chinese calendar promoters. That the parliamentary clock had accepted was surprising, that it lost was suspicious. Strong rumbles in the sporting fancy. Someone had slipped the monster timepiece a heavy envelope to lie down. London was now on Chinese time, with all serious punters refusing mah-jong bets involving politicians.

"It reminds me," said the time-battered pug, "of that night in New York I almost lost to the Union Square Clock Tower. My career would have been over if it hadn't been for some fancy photon-work."

Tactfully the Corinthian Jesuit drew us into Engelbrecht's confidence. "Your mother discovered that time isn't a dimension of space, but a field whose properties are affected by the nature of space existing within it?"

"Space a quality of time?" Sir Perkin snorted into his wine. Glinting rubies fell to the linen. But Cornelius's clever sourcing meant outright disagreement would be dangerous.

Clearing the cloth, Engelbrecht used a carpenter's pencil and the condensed mathematical logic developed at his famous Marrakesh asram to illuminate us. "Time alters when it interacts with space. In common with all observable nature, the Universe, or multiverse, grows organically and is best imagined as a vast tree, or perhaps even a forest with common roots."

"And the soil for this tree?" Float's reckless scepticism terrified us. Expensive watches would only be the first victims of our dwarf's distemper.

The tiny slugger observed philosophically that this was the level of logic he must commonly suffer. "An analogy," he growled. "There's a theory that the multiverse is creat- ed by the common will, but as to its origins...?" He cracked his knuckles. "I think therefore I thump."

Float's timid attention returned to the claret. The merest whisper of Big Bangs had him reaching for his jug.

Engelbrecht scowled reminiscently. "We're familiar with the disappearing neutron, we've recently learned how light can travel faster than light. Conventional method produces Heath Robinson physics turned into formulae by crazed Euclidians. At some point, as Columbus told the Pope, we have to let go of the premise that the world is flat."

"Can we see these alternative worlds?" 'Prof.' Aspinall had been kicking the gong around and wasn't ready for further shocks.

Cornelius embellished smoothly. "I understand it's a question of scale and mass. Put simply, millions of subtly different versions of our reality are separated by size. Each version, though scarcely different in terms of the multiversal compass, is as invisible to us as if we were only seeing a single magnified pixel out of a complex computer image. We never see the whole. It is either too small or too large. We coexist in the same space through scale. Each alternative world has

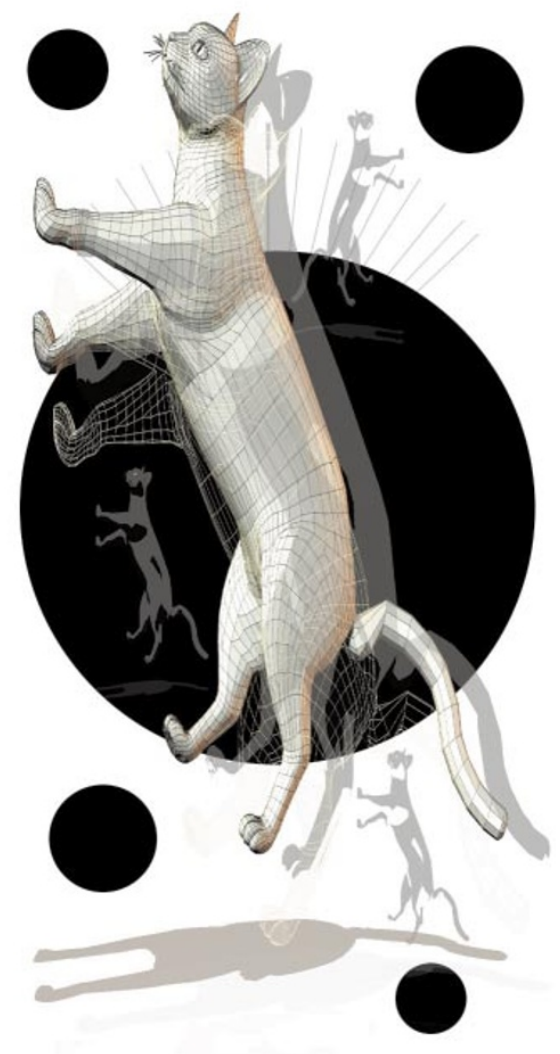

greater or lesser density and is invisible to the others."

"Proliferating to infinity. Whales, fairies," Engelbrecht paused, "dwarves."

"Space curves," mumbled 'Prof.' into his spoon. "Don't it?"

"Organically and often, as a branch curves." Cornelius smiled. "Like ourselves, space consists of spheres, but isn't itself spherical. Nature would be contradicted if it were. Certain entities somehow adjust their mass and move 'intrabranally'. For instance, few creatures are as expert at varying their size as cats. Thus their mysterious 'disappearances'. Happily the phenomenon hasn't occurred with dogs."

"Bigfoot, however..." 'Prof.' began.

"Cats," said Cornelius hastily, "see space invisible to us, coming and going through the multiverse pretty much at will."

"Bunkum," hiccuped Float. "We were supposed to hear about that New York match our dwarf won by a whisker. In funny circumstances."

Engelbrecht swelled. "A classy clock fighting for a consortium of Istanbul high rollers backing the Julian calendar. Twice my form and landing some tricky byzantine jabs. By Round 60 I'd borrowed all available time. I'm on my back looking like someone just unwrapped the Mummy.

"I've already squared the ref, of course. While shaving I've also dreamed up some insurance. Fortunately I have a prism hidden in one glove, a photon in the other. Resting on the count with my hands invisible I pull Harness's old baffled quantum trick. On nine. Works like a charm. Time hesitates. My seconds Coleman and Benford produce the mirror, rescaling mass and size to shrink the heavy bastard enough so I can stagger up and deliver the dynamite. Gravity completes the job. Down he goes. Dead weight. Space-time readjusts. It's all over. The Yankee Boomer's stretched full size on the canvas, his gobsmacked hands chasing themselves round his face. Cheering punters. GMT keeps the title!"

"Convincing," admitted Aspinall. "Except no way would Coleman and Benford help snatch a fix."

Engelbrecht winked. "Prof., you can't name a physicist in the multiverse who isn't in my pocket. Now, padre, your cats?"

"Oh, another time I think," said Cornelius, contentedly filling his pipe.

Float was at last profoundly asleep. Maurice Richardson's Exploits of Engelbrecht is republished by Savoy. Michael Moorcock's Multiverse is published by DC Comics. 